Casos Clínicos

Arch. Esp. Urol., 60, 2 (190-192), 2007

\section{RESTOS DE TEJIDO ADRENAL TESTICULAR EN LA HIPERPLASIA SUPRARRENAL CONGÉNITA (HSC): HALLAZGOS EN ECOGRAFÍA $Y$ RESONANCIA MAGNÉTICA.}

Elena Angulo Hervías, Gema Riazuelo Fantova, Irene Escartín Martínez y Juan José Castillo Escudero.

Servicio de Radiodiagnóstico. Hospital Universitario Miguel Servet. Zaragoza. España.

Resumen.- OBJETIVO: Mostrar los hallazgos característicos en ecografía y Resonancia Magnética (RM) testicular de los restos de tejido adrenal testicular en la Hiperplasia Suprarrenal Congénita (HSC).

MÉTODO/RESULTADO: Varón con HSC que acude a la consulta de urología por azoospermia. Se le realiza ecografía testicular observando lesiones nodulares heterogéneas en ambos testículos. Por los antecedentes del paciente se sospecha restos de tejido adrenal. Los hallazgos en RM testicular apoyan el diagnóstico. La regresión de las masas intratesticulares tras el tratamiento con glucocorticoides confirma dicha patología.
CONCLUSIONES: La presencia de una masa testicular en un paciente con HSC puede plantear un dilema diagnóstico en cuanto a realizar una biopsia testicular ó una orquiectomía para identificar dicha lesión. Con las técnicas diagnósticas por imagen como la ecografía y la RM testicular, los antecedentes clínicos de HSC y la regresión de las lesiones tras administrar glucocorticoides, se identifica este tipo de patología sin realizar otros procedimientos de carácter invasivo.

Palabras clave: Restos adrenales testiculares. Hiperplasia suprarrenal. Resonancia magnética.

Summary.- OBJECTIVE: To show the characteristic findings of testicular ultrasound and MR imaging in patients with congenital adrenal hyperplasia and testicular adrenal remnants.

METHODS/RESULTS: Male patient with congenital adrenal hyperplasia presenting with azoospermia. Testicular ultrasound showed heteroecogenic nodular lesions in both testicles. In view of the past medical history of the patient suspect of adrenal tissue remnants was raised. Testicular MRI findings supported the diagnosis. Regression of the intratesticular masses after glucocorticosteroid treatment confirmed the disease.

CONCLUSIONS: The presence of a testicular mass in a patient with congenital adrenal hyperplasia may pose a diagnostic dilemma in relation to perform or not testicular biopsy or orchyectomy to identify it. The combination of imaging diagnostic tests such as testicular ultrasound and MRI, the medical history of congenital adrenal hyperplasia and the regression of the lesions after administration of glucocorticosteroids allow to identify this pathologic entity without performance of other invasive procedures.

Keywords: Adrenal testicular remnants. Adrenal hyperplasia. Magnetic resonance imaging

\section{INTRODUCCIÓN}

La Hiperplasia Suprarrenal Congénita (HSC) está causada por un defecto enzimático autosómico recesivo, que en más del $90 \%$ de los casos es por el déficit de 21 hidroxilasa. Cuando esta enzima falla, los niveles de dos hormonas esenciales como el cortisol y la aldosterona disminuyen y sus precursores aumentan (17-hidroxiprogesterona, androstenodiona y testosterona). La disminución de cortisol en sangre provoca la elevación de la hormona adrenocorticotropa (ACTH) y como consecuencia se produce hiperplasia suprarrenal. Existen varias formas de HSC por déficit de 21 -hidroxilasa: la clásica (neonatal) con ó sin pérdida de sal, la forma tardía (con ó sin virilización) y la asintomática. 


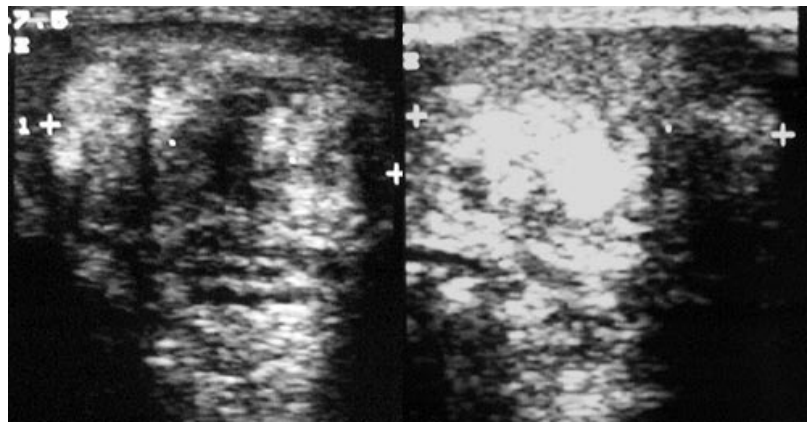

FIGURA 1. Ecografía de ambos testículos con una ecoestructura heterogénea.

El tejido adrenal ectópico se localiza en la región del plexo celiaco, los ligamentos anchos y en los ovarios fetales. Un cuidadoso examen microscópico indicaría que células de restos adrenales estarían presentes en los testículos de todos los varones con HSC. La elevación de la ACTH se ha postulado como la causa del crecimiento y actividad de esas células.

En algunos pacientes con HSC no diagnosticada ó no reconocida en la infancia, se presentan con una masa testicular que son restos adrenales. El diagnosticar a estas masas testiculares como restos de tejido adrenal en pacientes con HSC es importante porque el tratamiento de elección son los corticoides y no la cirugía como ocurre en la mayoría de las masas diagnosticadas en el testículo.

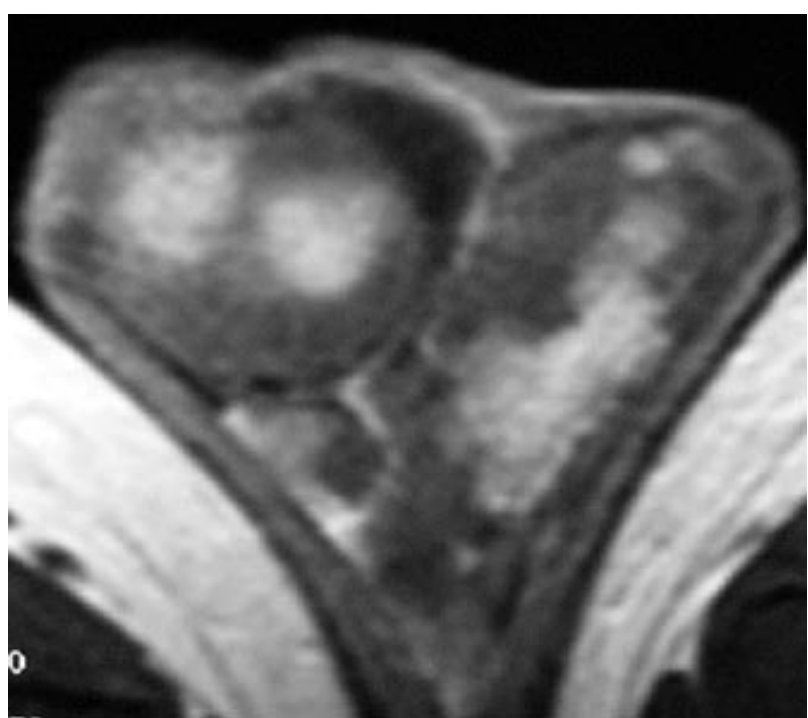

FIGURA 3. RM testicular. Corte axial de secuencia potenciada en $T 1$ tras la administración intravenosa de gadolinio con captación del contraste de las masas intratesticulares.

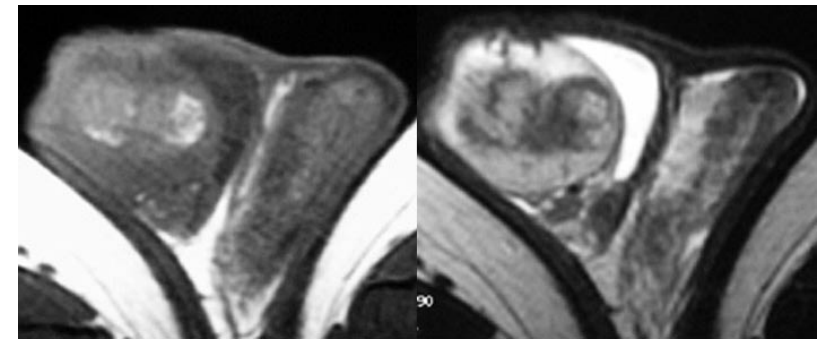

FIGURA 2. RM testicular. La imagen de la izquierda corresponde a corte axial de secuencia potenciada en TT, observando en ambos testículos unas masas levemente hiperintensas. La imagen de la derecha corresponde al mismo corte axial potenciado en T2, donde las masas son hipointensas.

\section{CASO CLÍNICO}

Varón de 42 años diagnosticado de HSC por déficit de 21 -hidroxilasa. Acude a la consulta de urología por azoospermia. Se realiza ecografía testicular (Figura 1), observando en ambos testículos unas lesiones nodulares de ecoestructura heterogénea de bordes imprecisos y mal definidos. Ante los hallazgos ecográficos, los antecedentes del paciente y la sospecha clínica de restos adrenales testiculares, se realiza RM testicular en secuencias Fast Spin Eco (FSE) T1 antes y después de administrar gadolinio intravenoso y secuencias FSE T2 en los planos axial, sagital y coronal. La RM pone de manifiesto la presencia de masas intratesticulares bilaterales levemente hiperintensas en las secuencias potenciadas en $\mathrm{Tl}$ e hipointensas en las secuencias potenciadas en T2 (Figura 2). El tamaño de la masa derecha es de 32 $\times 22 \times 19 \mathrm{~mm}$ y de $15 \times 15 \mathrm{~mm}$ la masa izquierda en la zona más gruesa, extendiéndose de forma alargada desde el mediastino testicular. Ambas masas presentan un importante realce tras la administración de gadolinio intravenoso (Figura 3). Al paciente se le trata con glucocorticoides habiendo buena respuesta con regresión de las masas intratesticulares.

\section{DISCUSIÓN}

Los restos de tejido adrenal testicular son una causa de masa testicular en pacientes con HSC no tratada ó no controlada. La presencia de una masa testicular -identificada durante una exploración física ó vista como un hallazgo incidental en ecografía- en un paciente con HSC puede plantear un dilema diagnóstico en cuanto a realizar una biopsia testicular innecesaria ó una orquiectomía.

El aumento de la 17-hidroxiprogesterona en vena espermática proporciona la información más concluyente; pero esta prueba no se encuentra disponible en la mayoría de centros hospitalarios. La utilidad de la biopsia 
testicular es limitada. El estudio histopatológico a menudo falla en resolver el origen del tumor, ya que es prácticamente imposible diferenciarlo del tumor de las células de Leydig sin la información clínica completa. Sin embargo, la presencia de cristales de Reinke y la existencia muy focal de lipofucsina son hallazgos más frecuentes en el tumor de células de Leydig, pero sólo aparecen en el $40 \%$ de los casos (1).

Los restos de tejido adrenal testicular se presentan con frecuencia como una masa palpable $(2,3)$. Ecográficamente se observan masas en ambos testículos localizadas en la región del mediastino testicular, siendo éstas hipoecógenas aunque también se han visto casos donde son hiperecógenas (3-5). La disminución del tumor en respuesta al tratamiento con glucocorticoides apoyaría el diagnóstico.

Los signos más característicos que aparecen en la RM testicular es que las masas aparecen isointensas respecto al músculo ó levemente hiperintensas en las secuencias potenciadas en $\mathrm{Tl}$; hipointensas en las secuencias potenciadas en T2 y una moderada captación tras administrar gadolinio intravenoso (6).

Los hallazgos por imagen que apoyan el diagnóstico de restos de tejido adrenal testicular en ecografía y en RM son los siguientes: localización periférica, sobre todo en el área del mediastino testicular; ausencia de distorsión del contorno testicular; y la bilateralidad de las lesiones (7).

Cuando se sospechan restos de tejido adrenal testicular, se debe realizar el seguimiento del paciente por técnicas de imagen -ecografía ó RM testicular- para valorar cambios en el tamaño. Si el tamaño aumenta, el paciente debe ser tratado con glucocorticoides.

\section{BIBLIOGRAFIAA y LECTURAS RECOMENDADAS ( lectura fundamental)}

1. WILSON, B.E.; NETZLOFF, M.L.: "Primary testicular abnormalities causing precocious puberty cell tumor, Leydig cell hyperplasia and adrenal rest tumor". Am Clin Lab Sci, 13: 315, 1983.

*2. RUTGERS, J.L.; YOUNG, R.H.; SCULLY, R.E.: "The testicular tumor of the adrenogenital syndrome: a report of six cases and review of the literature on testicular masses in patients with adrenocortical disorders". Am J Surg Pathol, 12: 503, 1988.

*3. WILLI, U.; ATARES, M.; PRADER, A. y cols.: "Testicular adrenal-like tissue (TALT) in congenital adrenal hyperplasia: detection by ultrasonography". Pediatr Radiol, 21: 284, 1991.

*4. AVILA, N.A.; PREMKUMAR, A.; SHAWKER, T.H. y cols.: "Testicular adrenal rest tissue in congenital adrenal hyperplasia: findings at gray-scale and color Doppler US”. Radiology, 198: 99, 1996.
5. SEIDENWURM, D.; SMATHERS, R.L.; KAN, P. y cols.: "Intratesticular adrenal rests diagnosed by ultrasound". Radiology, 155: 479, 1985.

**6. SCHNALL, M.: "Magnetic resonance imaging of the scrotum". Semin Roetngenol 28: 19, 1993.

**7. AVILA, N.L.; PREMKUMAR, A.; MERKE, D.P.: "Testicular adrenal rest tissue in congenital adrenal hyperplasia: comparison of MR imaging and sonographic findings”. AJR, 172: 1003, 1999.

Casos Clínicos

Arch. Esp. Urol., 60, 2 (192-195), 2007

\section{CARCINOMA INDIFERENCIADO DE VEJIGA CON PATRÓN DE LINFOEPITELIOMA. PRESENTACIÓN DE UN CASO.}

\section{Francisco Javier Torres Gómez, Francisco Javier Rivera Hueto y Francisco Javier Torres Olivera.}

Departamento de Anatomía Patológica. Hospital Universitario Virgen Macarena. Sevilla. España.

Resumen.- OBJETIVO: El carcinoma urotelial de alto grado con patrón de linfoepitelioma es una neoplasia infrecuente a nivel vesical en la que no se ha logrado demostrar relación con la infección por el virus de Epstein-Barr.

MÉTODOS: Presentamos el caso de un paciente de edad avanzada que tras presentar episodios de hematuria recurrente fue diagnosticado de esta singular entidad.

RESULTADOS: Se trata de neoplasias con gran componente linfocitario, en ocasiones mayoritario, que pueden prestarse a confusión histológica con procesos inflamatorios como cistitis crónicas e incluso con linfomas.

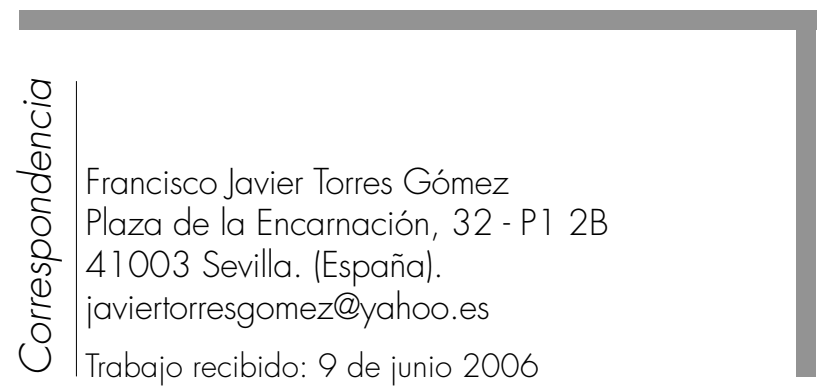

